\begin{tabular}{|c|c|}
\hline \multicolumn{2}{|l|}{ SCHOLARS: Journal of Arts \& Humanities } \\
\hline [Peer-Reviewed, Open Access, Indexed in NepJOL] & Central Department of English \\
\hline Print ISSN: 2773-7829; e-ISSN: 2773-7837 & Tribhuvan University \\
\hline Volume 1, August 2019, pp. 10-23 & Kirtipur, Kathmandu, Nepal \\
\hline DOI: https://doi.org/10.3126/sjah.v1i0.34444 & www.cdetu.edu.np/ejournal/ \\
\hline
\end{tabular}

\title{
Rewriting of the Past: Postmodern Intertextuality in The Peak by Sarubhakta
}

\author{
Min Pun, PhD \\ Department of English \\ Prithvi Narayan Campus, Pokhara, Nepal
}

\begin{abstract}
According to Linda Hutcheon, postmodern intertextuality desires to close the gap between past and present of the reader and desires to rewrite the past in a new context. The use of postmodern intertextuality in Sarubhakta's The Peak [an English translation from his original Nepali version short novel Chulee] has some relation with a fictional work from the past. There are some visible links between Sarubhakta's novel and Hemingway's short novel The Old Man and the Sea as both novels revolve around the theme of adventure. The major objective of this paper, therefore, is to indentify Sarubhakta's book as an adventure novel, having some intertextual connections with Hemingway's book. As a number of books in this category are surprisingly large, in this paper, only Sarubhakta's book has been studied making comparisons to Hemingway's book. Sarubhakta's novel is the text that adheres to postmodern intertextuality as it challenges the concept of originality and the question of whether rewriting another author's text is not a good piece of writing.
\end{abstract}

Keywords: Adventure fiction, postmodern intertextuality, mountaineering, rewriting

"In life, some get tired climbing the mountain; some get tired without climbing the mountain. In the lives of those who climb the mountain there is tiredness but there is no life in tiredness." (Sarubhakta 34-35)

"One danger follows another; a long series of dangers. This what life is; this what mountain is. Those who do not understand the mountain look at the mountain with animosity; those who do not understand life look at the life with animosity." (Sarubhakta 57) 
Rewriting of the Past: Postmodern Intertextuality 11

\section{Introduction: Sarubhakta as a Postmodern Writer}

The twenty-first century is the world of unrestrained consciousness and endless experimentations. The quotes above reveal the fact that human civilization has seen an unimaginable development of consciousness that has experienced unforeseen changes in spheres of various activities. Its impact has obviously been apparent in contemporary Nepali fiction. We have also seen an incongruity between the new culture that has evolved out of changes and the culture that has long been in the society.

Many Nepali novelists have attempted to explore and establish new centres. Their characters are no more stereotypic with a linear role playing such as the role of a landlord, a bourgeoisie, a pretty girl, or a protagonist representing one of high caste groups. Similarly, the Nepali readership is not troubled by such elements but by the consumerized culture of the twenty-first century. These are some of the unique and postmodern features that Sarubhakta's literary works have. If someone goes through his works such as Paagal Basti, Taruni Kheti, Samaya Trasadi and The Peak will explore new centres which represent the spirit of the new age, that is, the postmodern age.

Sarubhakta's latest English translation The Peak is inspired by mountains. He has utilized adjectives that can be used to describe the mountain: solitary, ancient, vast and God-like. Here, like rivers often represent the flow of life, the mountain represents a part of the planet built on nature's awesome violence.

In general, many books on mountains fall into the genre of mountaineering memoirs, of which the authors are certainly one of the most famous ones. For instance, Sarubhakta's The Peak is one of the books in which the mountain is the focus (Pun, para. 7). The book sits in the shadow of a mountain. It is like the mountain-as-muse works of William Wordsworth and the English Romantics. In Sarubhakta's book, the role of the mountain is multifarious. In it, the mountain can be symbolic or metaphorical, simply providing a dramatic setting. It can be a friend, or, in the case of Sherlock Holmes who met his death at the Reichenbach Falls in the Swiss Alps. So the mountain can sometimes be a killer.

Sarubhakta's The Peak, published in September 2012, is a short novel translated into English by Subhash Ghimire. The Nepali version is included in the university curriculum in Nepal. Sarubhakta has received the most prestigious literary award, the Madan Puruskar, in 1991, for his novel Pagal Basti. He has also won numerous other literary awards for his contribution in the field of Nepali literature. Through his works, he is critical of human nature as obscure because the individuals look hideous. Through his characters portrayed in his works, he has presented human beings as creators of society as per their needs. His vivid depiction of inner psychology of human beings truly projected in his works. 
Rewriting of the Past: Postmodern Intertextuality 12

Seen as a postmodern writer, Sarubhakta's works, such as The Peak, give an insightful perspective on contemporary Nepali fiction. He is noted for his openness and textual playfulness in foregrounding the indeterminacy of reality, identity, history and so on. Most of his works are self-reflexive and consciously imitative and often surrealistic. This paper examines the use of postmodern intertextuality in Sarubhakta's The Peak, in which he has great influence of Earnest Hemingway's short novel The Old Man and the Sea.

\section{The Concept of Intertextuality: A Postmodern Approach}

Postmodernism is an umbrella term that is used in different ways by different theorists. It has several common features to characterize its art forms. The notion of intertextuality is one of the prominent aspects in many postmodern art forms that refer to each other through pastiche, parody, irony, allusion, or imitation. So these postmodern forms are frequently used together to break conventions, which is one of postmodernism's distinct approaches to works of art.

Drawing oneself in search of meaning of intertextuality is a difficult task. There are many others who have defined the concept of intertextuality in different ways after Kristeva coined this word. Simply, the notion of intertextuality refers to any sort of presence in a text of another text. It means that a text is "a permutation of texts, an intertextuality in the space of a given text, in which several utterances, taken from other texts, intersect and neutralize one another" (qtd. in Allen 35). In order to add to this definition, he claims that the notion of intertextuality is "one of the most commonly used and misused terms in contemporary critical vocabulary" (2). In this definition, he asserts that there are so many different definitions of the word that to try and narrow them down to one ultimate definition would be a challenging project. William Irwin views that the concept of intertextuality is used to refer to "almost as many meanings as users, from those faithful to Kristeva's original version to those who simply use as it is a stylish way of talking about allusion and influence" (228). In this way, the notion of intertextuality is a postmodern approach that it is not necessarily a unified system, creating multiple definitions and meanings of the word.

Roland Barthes, a French literary theorist, viewed that there are two kinds of readers: 'consumers' who only read the text as it is and 'readers' who add their own ideas while reading and in that way new 'writers' of the text. He is famous for the idea of the 'death of the author', the statement of the reader being the writer. In his essay, he states,

... all writing is itself this special voice, consisting of several indiscernible voices and ... literature is precisely the invention of this voice, to which we cannot assign a specific origin: literature is that 
Rewriting of the Past: Postmodern Intertextuality 13

neuter, that composite, that oblique into which every subject escapes, the trap where all identity is lost, beginning with the very identity of the body that writes. (2)

Here, he means to say that it is the reader that provides the text with its meaning by introducing the voices of other texts and creating 'this special voice.' In order to judge a text, the literature history and writer's biographies are taken as the main source for evaluation.

Barthes claims that the way people view literature is tyrannically centred on the author as passion, his or her history and his/her passions. The sole voice of a text is not the author nor can the critics use the author of a work to explain the work itself. He sums up his essay at the end as stating that "there is one place where this multiplicity is collected, united and this place is not the author, as we have hitherto said it was, but the reader: the reader is the very space in which are inscribed without any being lost, all the citations a writing consists of" (7). This gives emphasis on the reader as well as intertextuality. The reader is the most important person, not the author. He stressed on the reader and how the reader uses past texts while reading.

Jean Francis Lyotard defines the term 'intertextuality' as a postmodern approach to art forms. He opines that postmodernism is the intertextual interaction of art forms as "incredulity toward matanarratives" (xxiv). Here, a metanarrative is a concept that gives a holistic knowledge, appealing to universal truth or value. This means that intertexuality as a postmodern approach is to shape a text by other texts. So it is almost impossible to read a text without being influenced by other texts that have read previously. Like Lyotard, Julia Kristeva states that intertextuality deals with the idea of how one text is shaped by a number of other texts and how readers might perceive the same text in different ways, depending on their reading history (qtd. in Smith 3). If the definitions of Lyotard and Kristeva are taken together, the term 'intertextuality' is the way of text's borrowing of other's words and ideas. It refers to the writer's borrowing and transformation of a prior texts or lines. So any piece of work becomes "a permutation of texts, an intertextuality in the space of a given text, in which "several utterances, taken from other texts intersect and neutralize one another" (Kristeva 36). Here, she argues that the denotative meaning of intertextuality involves two implications: One, the writer is a creator of the texts after he or she becomes a reader of the texts, meaning that any text is influenced by references, quotations and other impressions. Two, any text exists if it is read by others as it the reader creates the meaning of the text. In this way, both axes of intertextuality, texts entering through authors and texts entering through readers are both emotionally and politically charged. Kristeva further illustrates it in her book Desire in Language: A Semiotic Approach to Literature and Art: 
Rewriting of the Past: Postmodern Intertextuality 14

The notion of intertextuality replaces the notion of subject when we realize that meaning is not transferred directly from writers to readers but instead is mediated through, or filtered by, "codes" imported to the writer and reader by other texts. Intertextuality refers to text in terms of two axes: a horizontal axis connecting the author and reader of a text and a vertical axis, which connects the text. (69)

Kristeva here opines that uniting these two axes produce shared codes: every text and every reading depends on prior codes. She declares that every text is relational from the other discourses which impose a universe in it. She states that one should study the structure of the text. This involves citing it within the totality of previous or synchronic texts of which it was a transformation as she states that "any text is constructed as a mosaic of quotations; any text is the absorption and transformation of another" (66). It means that each text is connected to many other texts in one or the other way.

In literature, intertextuality basically means to refer to a text for a second book by title, scene, theme, character or storyline, or when a book refers to a social text such as media social or cultural story. Thus, intertexuality means the text within which other texts reside or echo their presence. To define intertextuality is to bring out this complex embeddedness of a narrative's meanings in the culture from which it comes. In many contexts, intertextuality can be contrasted with another term 'transtextuality' which refers to interrelationship between two particular texts while 'intertextuality' refers to one text's relationship with more texts by memories, echoes, or transformations of other texts.

Postmodernism, taken as post-history, refers not to specify historical developments but to the process of history. Many postmodern writers disrupt the continuity of their discourse by making it timeless fable. The ending or existence of the postmodern narrative has multiple meanings. The novels end with multiple interpretations unlike close ending of traditional novels. The novels of postmodernism are avant-garde and experimental in their forms. H. Porter Abbot, in his book The Cambridge Introduction to Narrative, discusses about the subversive nature of narrative in this way:

Narratives ... draw on pre-existing genres and that they imitate or allude to pre-existing genres and that they imitate or allude to preexisting narratives. But the term imitation and allusion shift the emphasis from an inescapable intertextual web that generates the narrative and produces its effects to an inescapable intertextual web that generates the narrative and produces its effects to an individual distinct narrative, shaped by an author through a process of skillful selection. Where intertextuality tends to minimize the author's role and distinctive 
Rewriting of the Past: Postmodern Intertextuality 15

wholeness of the work, allusion and imitation tend to the reverse:

featuring the author's control and the singular wholeness of the work.

(94-95)

Thus, intertextuality in any narrative has to be seen in association with the whole complex issue of the reader's varied expectations as formed by ideological and generic polarization.

In many postmodern novels, the fragmented plots are to some extent conditioned by the temporal speed of the late capitalist technologies of production and consumption. Time has become a fundamental element to organize narrative as David Harray in his The Condition of Postmodernity states, "Time becomes human to extend that it is articulated through a narrative mode \& narrative attains its full meaning when it becomes a condition of temporal existence" (32). The postmodernists show the multiplicity of possibilities by dividing and subdividing the time to do so, as they use repetition and experimental typographies. Repetition is a general feature of all kind of narrative forms. The identical scenes are repeated and presented almost the same words every time. Only slight variations distinguish one description from the other. It is impossible for the postmodern reader to reach a coherent image of the actions that underlay the repetitions. It focuses on the microstructure of the time. The microstructure of time does not bridge the gap but rather it splits the things.

So this paper is to explore this pluralistic condition of reading and practice theoretical interventions in the use of intertextuality as used by the modernist writers. This intervention, as mentioned by Linda Hutcheon, is 'postmodern intertextuality'. She argues that postmodern intertextuality is "a formal manifestation of both a desire to close the gap between past and present of the reader and a desire to rewrite the past in a new context” (qtd. in Murphy 76). It clearly means that the reader actively searches out the work's links with its sources and produces a new reading of both the present and past texts. She further clarifies the term as it "replaces the challenged author-text relationship with one between reader and text, one that situates the locus of textual meaning within the history of discourse itself" (125). In the same book, she further argues "A literary work can actually no longer be considered original; if it were, it could have no meaning for its reader. It is only as part of prior discourses that any text derives meaning and significance'” (126). So, postmodern issues are dealt with intertextuality of texts.

The use of postmodern intertextuality in Sarubhakta's The Peak is hinted while going through the novel. The novel depicts some relation with the novel from the past. There are some visible links with Hemingway's The Old Man and the Sea which is very similar to the concept of intertextuality. Sarubhakta problematizes the status of author and his or her creation. As it is the feature of postmodernism, where nothing is uniform 
Rewriting of the Past: Postmodern Intertextuality 16

and continuous, so is postmodern intertextuality trained of depicting varying storylines, themes and characters in the same novel.

\section{Sarubhakta and Hemingway: What Is in Common?}

Sarubhakta, the pen name of Bhakta Raj Shrestha and born in 1956 in Pokhara, is a celebrated novelist, poet and dramatist of Nepali literature. He realized that it is human who makes society and has concretized it according to their own needs as Pradhan states that Sarubhakta "being a mountain himself while looking at the mountain he himself gets the height of the mountains" (8). So Sarubhakta made a piercing analysis of human psychology and his novels are the vivid depiction of his outlook.

Sarubhakta's The Peak focuses on the protagonist, Sarubhakta himself, as the narrator and the mountaineer. The protagonist struggles with a mountain peak far out into the Mount Everest. The story is about an epic battle between the protagonist and the mountain said to be the biggest goal of his life, providing "details of the mountainous surroundings and mountain climbing” (Ghimire 11). The book opens with this background that the narrator has gone weeks for the base camp, another weeks for climbing the mountain and yet another weeks for climbing down the mountain. The protagonist begins his venture alone into the Mount Everest, carrying the climbing kits with him. As days and nights go, the protagonist comes across the more difficult journey ahead because there is extreme cold as he feels lack of sufficient oxygen to breathe. As he moves up the mountain peak, he is completely exhausted and even in delirium. Ultimately, he reaches the peak and stands up at the top of the world though this was like the long epic battle to complete his mission.

Sarubhakta's protagonist experiences the most difficult struggle for life as he continues his journey back to the base camp. For instance, the protagonist has to struggle with the ice storms; he is hit by the ice rock; even he faints while climbing down the mountain. In this way, on the way back to the base camp, he dies as an undefeated hero because he once reached the top of the world. While dying he also hopes that the future countrymen will continue the legacy of bravery and struggle that he has left behind the mountain trails.

Born in Oak Park, Illinois in 1899, Hemingway was one of the most famous American novelists, short-story writers and essayists of his time. He is known for his simple style as many other writers are influenced by this style. He won the Noble Prize for literature in 1954. During the First World War, he joined a volunteer ambulance unit in Italy and was acknowledged by the Italian government for his service. He suffered a severe leg wound in 1918. He committed suicide with his favorite shotgun at his home in Ketchum, Idaho on July 2, 1961. 
Rewriting of the Past: Postmodern Intertextuality 17

Hemingway's The Old Man and the Sea is about "an epic battle between an old, experienced fisherman and a giant marlin said to be the largest catch of his life" (Yasmin 79). In the story, the protagonist Santiago goes fishing into the sea for eighty four days, but he cannot catch a single fish. He is accompanied by Manolin, Santiago's young apprentice, but Santiago sets out alone into the sea on the eighty fifth day and could catch a marlin by noon. As he spends two days and nights, he battles with the marlin by using his full strength to pull the fish onto its side. On the eighty sixth day, he is so tired and in delirium that he stabs the fish with a harpoon. As he continues his journey back to the shore, many sharks are attracted to the trail of blood left by the marlin in the water. First, he kills a huge shark with a harpoon. He then kills five other sharks and many others are driven away. But by night, the sharks have almost eaten the marlin's entire carcass, leaving a skeleton which is eighteen long. The story ends with his reaching the shore as people nearby cafe mistakenly take the skeleton of the marlin for a shark.

One of the best ways to understand Sarubhakta's The Peak is by reading Hemingway's The Old Man and the Sea together, using the postmodern intertextual perspective. Interestingly, books by Sarubhakta and Hemingway are, by chance or by design, fictional works with similar plots, characters and themes in spite of the fact that the contexts and time are quite dissimilar. Both Sarubhakta's book and Hemingway's book are masterpieces of literature, which show human's struggle to win livelihood from Nature and against Nature. Both works share a common theme, that is, human's struggle to win livelihood: one earns from the mountain and the other from the river. Both Hemingway's Santiago and Sarubhakta's protagonist have to live and feed alone; both of them are destroyed but not defeated. Both triumph over every obstacle with the power of their love for own professions. And in both, Nature is their friend and also opponent force. Like Hemingway's Santiago character, Sarubhakta's protagonist no more dreams of any fortune or romance; both struggle only to survive.

\section{Rewriting of the Past in Sarubhata's The Peak}

A body of literature has developed around one of the humankind's mountaineering topics. Much of this writing is concerned with the reporting of explorative accomplishments; however, a significant amount is devoted strictly to narratives of climbing adventures in the mountains. This genre of literature can be considered as mountaineering fiction, which is also called 'adventure fiction'.

Many novelists have utilized many standard techniques for plot development in writing the mountaineering fiction. These techniques include adventure, mystery, romance, melodrama, etc. In fact, mountaineering is identified as a thrill sport, so adventure thriller is understandably a popular form for the mountaineering novel. 
Rewriting of the Past: Postmodern Intertextuality 18

The mystery thriller is a popular form for the mountaineering novel. Since accidental deaths in the mountains, while infrequent, do occur, many novelists use this tragedy to develop the story line where murder is made to appear an accident (Pokorny 122). One of the earliest novels using this theme and a classic mountaineering novel is A.E.W. Mason's Running Water which was published in 1907. Mason was an accomplished mountaineer and quite familiar with climbing in the Alps. This was the setting for his story of villainy in the mountains. The action builds up to a dramatic climax between the protagonist and his intended victim on the ascent of the Brenva Ridge of Mont Blanc. The description of the route and the climbing are stirring and believable. Another mountaineering novel of Mason is A Romance of Wastadale published in 1923 takes place in the English Lake District, a story of lone rivalry with an ingenious murder on the cliffs of Scafell.

The individual reactions to hazards, tensions and difficulties in mountaineering and the interaction under stress with other personalities are some of the elements in the psychological mountaineering novel. An example is Hugh Merrick's The Breaking Strain published in 1950 where poor mountaineering judgement tests the breaking point of men, women and ropes. Another story in this class is Ethel Mannin's Men Are Unwise published in 1934, a story of a man's obsession with the mountains, who because of his financial circumstances is unable to do serious mountain climbing. He eventually gets to the Alps and his behavior in the mountains is a fascinating mixture of irony and paradox.

Many of this type of novels use the mountains as a setting such as for plot development. One outstanding example of this form is James Hilton's Lost Horizon published in 1933. In this novel, the action takes place in the mountains, creating mood for the story. It is a powerful story that added Shangri-la to our vocabulary.

In 1939, Ruthven Todd wrote Over the Mountain, a mountaineering novel with strong political overtones. It is a satirical work written in Orwellian style which parodies all the insane madness going on in Europe just prior to the outbreak of the Second World War. The book is quite scarce because most of the copies were destroyed during the London blitz.

Not all mountaineering fiction is serious, suspenseful or philosophical: humour is also used in a number of novels and short stories. An early story in this vein is Alphonse Daudet's Tartarin on the Alps published in 1888, later examples being W.E. Bowman's The Ascent of Rum Doodle published in 1937 and a delightful short story by H.G. Wells, Little Mother up the Morderberg.

An unusual style for the mountaineering novel is the unfinished, thoughtprovoking and surreal novel by the late avant garde poet, writer-philosopher Rene Daumal, Mount Analogue, published in 1952. The story of the novel is subtitled in this way: "A novel of symbolically authentic non-Euclidean adventures in mountain 
Rewriting of the Past: Postmodern Intertextuality 19

climbing," which is strange. It is about a group of strange characters who set out to climb a symbolic mountain higher than the Mount Everest. The novel has touches of both physics and metaphysics, yet is neither science fiction nor mystic, although an appreciation of all these elements has enhanced the reader's understanding of this book.

While many of the books in the genre of mountaineering fiction are interesting reading and some are quite well written, the really excellent mountaineering novel has yet to reach us. For instance, James Ramsey Ullman wrote The White Tower in 1945 on the theme of mountains. The novel became an important work of art that introduced mountaineering as a subject matter for the fictional work. It is a story of mountaineering for those readers who do not engage in climbing. When it was published, it aroused a lot of interest of many non-climbing reading public to go mountaineering activities.

Mountaineering fiction like any fiction needs to satisfy some common basic conditions for the reader, who to quote de Maupassant, asks of the novelist: "Console me, - make me sad, sentimental, - make me dream, - make me laugh, - make me tremble, - make me weep, - make me think” (qtd. in Pokorny 126). The great peaks continue to succumb on all sides to the efforts of expert climbers using advanced techniques to assist them. It remains to be seen if a great mountaineering story will be created using a new and imaginative writing approach.

Sarubhakta's The Peak is a successful mountaineering fiction in Nepali literature. While some other mountaineering fictional works by some other writers use the mountains simply as a setting in which the plot takes place, his work is one outstanding example of this form. As for Pradhan, while reading it, "one doesn't feel fiction but reality" (7). So the mountains are important to the story only as they serve to constrain the action to a particular location and create mood. It is admitted that much of his focus in this novel is concerned with the reporting of explorative accomplishments; however, a significant amount is devoted strictly to narratives of climbing adventures in the mountains.

Sarubhakta's novel is a good example of postmodernist adventure fiction that shares a richly intertextual relationship with Hemingway's The Old Man and the Sea and written in the very believable language even though its plot is fairly complex with a lot of digression. It is a story about the climb of an incredibly difficult Nepali mountain north face direct. The descriptions of climbing on ice and snow-covered rock and the stream-of-consciousness narrative technique, is a brilliant piece of creative effort and results in a mountaineering novel of first class proportions.

In fiction writing, the literature of the mountains is an important genre. In sport, mountaineering is considered as a thrill sport, but in fiction writing about the mountains, its readers expect a lot of adventure and excitement (Pokorny 121). In contrast, Sarubhakta has used the mountains to write his work The Peak that makes his book as an 
Rewriting of the Past: Postmodern Intertextuality 20

adventure fiction. Most importantly, his work is the factual accounts of mountaineering achievements that has so much more evocative and thrilling than any invented happenings revolving around imaginary characters. He is perfectly competent enough to produce a story in which the situations and details are authentic and free from the monotony of the factual writing.

Sarubhakta, through his protagonist, has unfolded the fact that every living creature has to face the struggle which is the inevitable force in life and no one can escape this encounter. But the struggle, the author suggests, is never an end in itself: in the struggle, there is always the possibility of the most vigorous life. Presenting the main reason of struggle in life, the novelist argues through the words of the protagonist in this way: "Some keep coming in the mountain. Storms keep coming in life. One needs to fight with the storms bravely. One cannot survive from the storm by escaping from it. If from the beginning of the creation, there is an existence of the storms, they have their meanings too" (72). This indicates that the protagonist is reinvigorated by his struggle with the mountain and believes that "irrepressible struggle of human beings will not stop" (74). This proves the fact that there is the possibility of life and life has to follow on the heels of fighting. Additionally, the novelist claims that there are risks in the mountains as there are risks in human life as well. Here, the mountain is compared with the human life, suggesting that every living creature has to fight for life. According to the novelist, all creatures on earth have to face risks every day as he mentions, "This is what life is; this is what mountain is" (57). So without struggles in life, there is no meaning of life, too. In the novel, the imagery of mountain is used to emphasize the cyclical links between life and struggle, or life and death as his protagonist fights with the mountain. The mountain is vividly depicted as a living creature. The protagonist of the novel again describes about the relationship between life and the act of climbing in the following lines: "In life, some get tired climbing the mountain; some get tired without climbing the mountain. In the lives of those who climb the mountain there is tiredness but there is no life in tiredness" (34-35). According to the protagonist, doing something in life brings life alive and meaningful. Climbing the mountain is one such an instance. In this way, the protagonist of the novel is certain that the future generations will follow his footsteps and learn the meaning of life from him although the protagonist has died long before.

Now, if seen these two texts together from the postmodern intertextual perspective, they stand in relation to one another. For instance, both Hemingway's Santiago and Sarubhakta's protagonist show great struggle to earn their livelihood. Both of them are destroyed but not defeated. They are successful because they are passionate about their profession. For instance, at first, Santiago shows his patience for eighty four days without catching a single fish, but as he catches a huge marlin, he shows his strength to drag the fish towards the shore. Similarly, he opposes when he is attached by 
Rewriting of the Past: Postmodern Intertextuality 21

the sharks at first, but he feels sympathetic to the sharks later. In this way, both Sarubakta's protagonist and Hemingway's Santiago try their level best to manage a somewhat comfortable life. These two literary pieces are very famous in the two worlds of literature. Nature is their friend and also opponent force. They try to triumph over Nature. Santiago’s struggle is called an “epic struggle” (Yasmin 84). Sarubhakta’s protagonist always fights against all obstacles, poverty, neighbours, all deprivation, natural calamities, etc., but Hemingway’s Santiago opines, "No good book has ever been written that has in it symbols arrived at beforehand and stuck in. ... I tried to make a real old man, a real boy, a real sea and a real fish and real sharks. But if I made them good and true enough they would mean many things” (qtd. in Keast, par. 3). In the same manner, we can be certain that Sarubhakta also created a real climber, a real mountain and a real struggle of a climber. Both texts deal with those people who struggle for life and become alive. It proves that all the human beings' feelings are almost the same; only difference is their language.

Both The Peak and The Old Man and the Sea deal with the real essence of human lives such as trying to keep others happy and content. They are tired of quarrelling for their rights with family members and neighbours for their survival. They frequently fight for their survival, not by any other means. Life means only to hunger and thirst. They will start a new life. We see in Sarubhakta's climber's eye the indomitable spirit of Santiago: "But man is not made for defeat. A man can be destroyed but not defeated" (Hemingway 103). Thus, a rich intertextual background used in Sarubhakta's The Peak builds the novel by Hemingway into the intertext of world literature as the notion of postmodern intertextuality is one way or the other inevitable for all texts.

\section{Conclusion: The Use of Postmodern Intertextuality}

The triumph of an historic climbing can be painfully affected by the perilous descent. The conquering spirit of modern climber has taken mountaineering to faraway places to climb mountains by ever more difficult means; one outstanding legacy is a rich narrative of text for the author. This is as true nowadays as it was during the infancy of writing of mountaineering literature.

Sarubhakta has given us The Peak, a pioneering book in Nepal about the mountains, comparable in quality with other mountaineering books. In future, the mountains can be an ideal setting for a noble and serious work of adventure fiction in Nepali literature. In the words of its translator Subhash Ghimire, Sarubhakta's book would be "the source of inspiration to all and may the inhabitants of the mountains start writing on mountains" (12). Thus, the mountains can be used as the adventure scene, but not to the best advantage. 
Rewriting of the Past: Postmodern Intertextuality 22

As mentioned above, Sarubhakta's The Peak exploits intertextual references from Hemingway's The Old Man and Sea. Both Sarubhakta's book and Hemingway's book are to show human struggle to earn and win livelihood from Nature as well as against Nature. This paper has shown the similarities of two opposite worlds' protagonists' struggle to win livelihood. One earns from the mountain and the other from the sea. But both of their struggles are almost the same. One is old and other is young. Santiago has to live and feed alone but Sarubhakta's climber has to maintain a family. As these two books have more in common, Sarubhakta's book can be read in different interpretations as rewriting of Hemingway's text. The use of postmodern intertextuality in Sarubhakta's book is to show hidden references in the novel. In this way, the paper has exclusively focused only on the struggle of the protagonists of both texts to collect their livelihoods, enabling to single out the key features of the postmodernist intertextuality in Sarubhakta's book.

To conclude, The Peak by Sarubhakta is a good adventure story as it rewrites the past in a new context. The use of postmodern intertextuality in this work is to have a desire to close the gap between past and present of the two contexts. In this adventure, unlike other mountaineering novels, the rope required cutting. After surviving a fall into a crevasse on Nepali Himalayas, Sarubhakta's climbing partner was literally forced to break the bond between the climber and the narrator, leaving the climber almost for dead. Remarkably, despite horrendous injuries the climber was able to crawl down the mountain to survival in order to serve for deepening the original perspective of the text as postmodern intertextuality is a concept that can connect different literary texts across cultures, regions and languages.

\section{Works Cited}

Abbot, H. Porter. The Cambridge Introduction to Narrative. Cambridge UP, 2002. Allen, Graham. Intertextuality. Routledge, 2011.

- - -. Pastiche in Frederic Jameson's Postmodernism. Duke UP, 1991.

Awung, Stephen. "Intertextuality in Literature, Film and Other Popular Media: Intermediality and Signs Relations.” Grin, 14 April 2002, www.grin.com/document/107559

Barthe, Roland. "The Death of the Author.” Translated by Richard Howard. UbuWeb/UbuWeb Papers, 1992, www.tbook.constantvzw.org/wpcontent/death_authorbarthes.pdf

Ghimire, Subhash. "Preface.” The Peak, translated by Subhash Ghimire, Sahityakar Sarubhakta Sarokar Kendra, 2012, pp. 11-12.

Harvey, David. The Condition of Postmodernity. Blackwell, 1989. Hemingway, Ernest. The Old Man and the Sea. Friends' Book Corner, 2005. 
Rewriting of the Past: Postmodern Intertextuality 23

Hutcheon, Linda. The Politics of Postmodernism. $2^{\text {nd }}$ ed. Routledge, 2002.

Irwin, William. "Against Intertextuality." Philosophy and Literature, vol. 28, no. 2, October 2004, pp. 227-242, Project Muse, www.muse.jhu.edu/article/175070/pdf

Keast, Michael. “An Old Man and a Determined Woman.” Pied-a-terre CPH, 2013, www.piedaterrecopenhagen.wordpress.com/tag/the-old-man-and-the-sea/

Kristera, Julia. Desire in language: A Semiotic Approach to Literature and Art. Edited by Leon Roudiez and translated by Thomas Gora, Alice Jardine and Leon S. Roudiez. Columbia UP, 1980.

Lyotard, Jean-Francois. The Postmodern Condition, A Report on Knowledge. Translated by Geoffrey Bennigton and Brian Massumi. Mancehster UP, 1984.

Murphy, Shane. "Obliquity in the Poetry of Paul Muldoon and Medbh McGuckian.” Poetics, vol. 31, no. 3 \&, Fall/Winter 1996, pp. 76-101, www.muse.jhu.edu/article/666877/summary

Pokorny, George. "Fiction in Mountaineering Literature.” Alpine Journal, vol. 85, no. 329, 1980, pp. 121-129.

Pradhan, Krishna Chandra Singh. “The Crampon Steps Must Keep on Going.” The Peak, translated by Subhash Ghimire, Sahityakar Sarubhakta Sarokar Kendra, 2012, pp. 5-9.

Pun, Min. "Sarubhakta's The Peak and Mountaineering Fiction in Nepali Literature." Nepali Kalasahitya Dot Com Pratishthan, 2014, www.nepalikalasahitya.com/index.php?option=art\&page=artdetail\&aid=303531 36363134 \&lang $=\& p g g=1 \&$ asc $=3035633134$.

Sarubhakta. The peak. Translated by Subhash Ghimire, Sahityakar Sarubhakta Sarokar Kendra, 2012.

Smith, Anna Jean. Reading Julia Kristeva: Estrangement and the Female Intellectual. PhD Dissertation. U of Canterbury, 1992, www.core.ac.uk/download/pdf/35464218.pdf

Yasmin, Shegufta. "Struggle of Santiago and Kuber: A Comparative Study between The Old Man and the Sea and Padma Nadir Majhi." ASA University Review, vol. 6, no. 1, 2012, pp. 79-84. 